\title{
Effect of Preventive Maintenance on Machine Reliability in a Beverage Packaging Plant
}

\author{
Jacob Ben, Papua New Guinea University of Technology, Papua New Guinea \\ Aezeden O. Mohamed, Papua New Guinea University of Technology, Papua New Guinea \\ Kamalakanta Muduli, Papua New Guinea University of Technology, Papua New Guinea \\ https://orcid.org/0000-0002-4245-9149
}

\begin{abstract}
This paper investigates the effect of preventive maintenance on the reliabilities of devices in a bottling plant. Six months of real-time maintenance data were analyzed quantitatively. Based on the breakdown events obtained for each machine, mean time between failure (MTBF), mean time to repair (MTTR), and failure rate $(\lambda)$ values for individual equipment are calculated. The bottle packer, empty bottle inspector (EBI), and palletizer are identified as the plant's critical machines. A breakdown analysis (BDA) is then performed on the bottle packer and from the failure mode of all the reoccurring problems affecting this machine as a result of ineffective PM. An autonomous maintenance (AM) team is set up as part of establishing an effective PM program to improve the reliabilities of the critical machines that were continually falling. A significant reduction in machine breakdowns is observed after two months of rolling out the AM program. As a result, the reliability of bottle packer increased from $55.30 \%$ to $70.80 \%$, while EBI and palletizer increased from $89.20 \%$ and $87.20 \%$ to $92 \%$ and $90.50 \%$, respectively.
\end{abstract}

\section{KEYWORDS}

Corrective Maintenance, Failure Rate, Machine Breakdown, Plant Reliability, Preventive Maintenance

\section{INTRODUCTION}

With competition in the world continually increasing, organizations have been forced to adapt new competitive strategy (Galli, 2020). One such strategy is how to minimize production loss due to breakdown. Maintaining a breakdown-free production line is the goal of any manufacturing plant in ensuring its operating costs kept as minimum as possible. To conduct a reliable maintenance program has to be in place to maintain the machine and system in good working condition and that all necessary repairs done on time in full. The type of maintenance program applied can be divided into two categories: breakdown (emergency) maintenance and preventive maintenance. Breakdown maintenance deals with machines or systems after it has broken down and failed to perform its intended function. Preventive maintenance (PM), on the other hand, is time-based maintenance 
aimed at reducing or avoiding breakdowns and involves carrying out maintenance activities on a periodically scheduled basis.

One of the main challenge in developing a maintenance strategy with the constraints of availability of resources, is using the right-thinking framework (Galli, 2018a). These challenges are significant for small and medium sized plants those face lot of difficulty in their attempts in innovating maintenance strategies due to their small size and limited resources (Nikabadi, \& Hakaki, 2018). If done right, preventive maintenance has an immense potential to increase the reliability of a system, enhance machine up-time, minimize equipment breakdown, and improve the efficiency of production plants at low operating costs. Various activities (cleaning, inspection, lubrication, tightening, and replacement of worn parts) carried out under the PM program must have one aim, and that is to increase both the availability and reliability of all machines on the production plant. Machine reliability is increased by reducing its risk to fail, hence allowing the device to work correctly to perform its desired functions during a specified period under predetermined conditions (Kiyak, 2011). Availability is the proportion of time a machine is available out of the time it should be possible. It increased by minimizing unplanned downtime and changeover times. A well-maintained production plant will, therefore, have higher equipment availability and reliability hence be more profitable.

With preventive maintenance, the aim is to detect and prevent faults before they create disturbances in the machine and production system(Lagnebäck, 2007). As devices get old, their probability of failure increases much as specific parts and components begin to wear. At this point, leaving the equipment too long without any form of maintenance will result in a catastrophic failure. The desired preventive maintenance to perform on a machine influenced by several factors, including the level of technology, type of production processes, and the age and condition of the equipment. With a higher degree of PM planning and execution, the total breakdown and time losses of the plant can reduce significantly, thereby increasing the reliability and availability of the production system.

It is an accepted view that technological innovation is an extremely important factor to support industrial growth(Omamo et al., 2018) and sustained economic development of any country and perhaps the most important(Omamo et al., 2020). In this light study on development of suitable maintenance strategies for the industries from all industrial sectors assumes importance. This study is conducted to assess effect of PM on machine reliability in a beverage packaging unit which is scarce in previous literature. Further, the study is conducted in Papua New Guinea, hence, provides an opportunity to identify the importance of PM and relevant challenges over the long-term because, resources are in the case of developing economies typically much more limited, management much less committed and work methods much less organized than in the industrialized world(Haddad \& Otayek, 2019). Heineken South Pacific Brewery Limited in Papua New Guinea conducted a study from June to December 2019. The purpose of the study was to increase knowledge and evaluate the company's preventive maintenance program to decide if the level of planning, scheduling, and execution of maintenance activities was fulfilling the requirements for reducing machine breakdowns and time losses in the beer packaging plant. The research compiled quantitatively using real-time data collected from (1) the brewery's online production data recording software called IVAMs, and (2) historical breakdown data from the maintenance team. These were then compiled, tabulated, and in-depth analysis performed. A literature review was conducted as part of the research to compare the empirical findings with peer-reviewed information to ensure the quality of the study.

Based on the results of the study, conclusions made on the relationship between failure rates and ineffective or no preventive maintenance on machines on the production plant. Significant factors contributing to high downtimes on the plant's critical device identified, and counter-measures developed to prevent breakdowns from reoccurring, hence improving overall plant reliability. 


\section{MAINTENANCE STRATEGIES}

Maintenance defined as the combination of all technical, administrative, and managerial actions during the life cycle of an item intended to retain it in, or restore it to, a state in which it can perform the required function (Mkemai, 2011). In manufacturing, any equipment subjected to plant operations requires proper maintenance and repair to improve safety and production capacity. According to Mkemai (2011), several maintenance strategies are available and divided into two major groups, namely, preventive maintenance (PM) and corrective maintenance (CM). Preventive maintenance tasks, as stated by Mobley (2002), are intended to prevent unscheduled downtime and premature equipment damage that would result in corrective or repair activities. As discussed by Mkemai (2011), the two groups can subdivide into subgroups shown in Figure 1.

Corrective maintenance strategy has the lowest investment, the highest operating cost, and provides the lowest equipment availability (Adale, 2009). The sub grouped into deferred and immediate maintenances were according to Márquez (2007). Deferred is one in which CM has not immediately carried out after a fault is detected but is delayed based on given maintenance rules (e.g., lack of spare parts, budget cycle, and climate condition). When maintenance deferred, component, or system performance deteriorates rapidly, bringing the time at which failures are unacceptably frequent earlier in the system's life (Jessica, 2014). On the other hand, immediate maintenance is one where $\mathrm{CM}$ is carried out without delay after a fault has detected to avoid the unacceptable consequences of component or system failure (Adale, 2009).

Also known as time-based maintenance or planned maintenance, PM is a proactive type of maintenance strategy aimed at reducing or avoiding breakdowns through a program of cleaning, inspection, lubrication, tightening, and replacement of worm parts. The planned PM tasks, usually carried out at regular intervals when the equipment is still functioning, are performed before a failure has occurred(Hupjé,2018). If implemented correctly, PM can be very useful in preventing a machine or component from catastrophic failure, thereby minimizing the number of emergency breakdowns and machine downtime. However, if PM poorly planned and executed, equipment reliability will be low, thus leading to higher maintenance costs due to frequent malfunctions and procurement and replacement of spares(Olose, 2016).

Condition-based maintenance $(\mathrm{CBM})$, also referred to as predictive maintenance(PdM), is a preventive maintenance method carried out based on certain conditions of the machine. The machine conditions can be monitor continuously or periodically depending upon the need for the availability of the equipment(Morales, 2002). Real-time data indicating machine condition can acquire through monitoring techniques such as vibration measurements and analysis, oil analysis, infrared thermography, laser systems, and ultrasonic(Rao, 1996). Based on this data, maintenance activities

Figure 1. Classification of maintenance strategies (Mkemai, 2011)

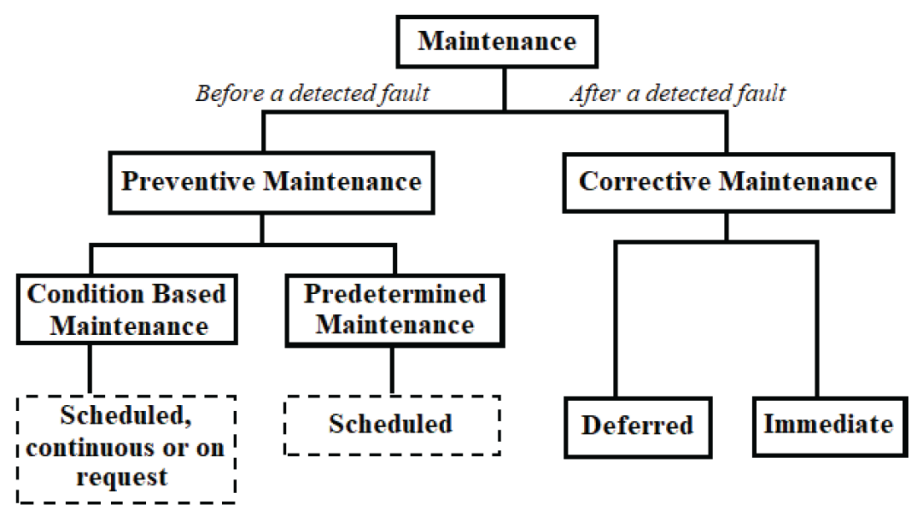


and resources prioritized accordingly. Since CBM utilizes real-time data to predict machine failure due to temperature, pressure, vibration, noise, humidity, and changes in the electrical and mechanical characteristics of critical equipment) it is much more cost-effective than maintenance on failure or scheduled maintenance(Mahmood, 2011). Scheduled preventive maintenance usually results in repairing or replacing components too early or too late, leading to support that is too expensive and ineffective in preventing breakdowns.

Predetermined maintenance, according to Swedish Standard Institute (2001), is maintenance carried out by established intervals of time or number of units of use but without previous condition investigation. The actions performed under this type of maintenance strategy are decided based on a predetermined rule, usually involving timing or a measure of usage(Noriega, 2019). Thus, preventive maintenance to be performed is either clock-based or usage-based actions. In clock-based keeping, the preventive actions conducted at specified calendar times, for instance, overhaul every first quarter of the year. With usage-based maintenance, scheduled PM activities based on the number of specific production metrics like operating hours, name of products made, and several processed parts (Nieminen, 2016).

\section{MACHINE RELIABILITY AND MAINTAINABILITY}

\subsection{Reliability}

Reliability engineering measures and improves resistance to failure over time, estimates expended life, and predict time to failure of equipment or a component . There are two overlapping reliability themes for modeling life and performance of items; these are data/evidence-driven and physicsdriven. Evidence-driven reliability analysis relies on probabilistic and statistical methods and based on collecting data and assessing future behavior of things based on past occurrences of failure or performances. On the other hand, physics-driven reliability analysis based on the physics of failure. This model of failure has an empirical representation of the physics of how a machine or component degrade and is established through a significant amount of knowledge and testing to understand the underlying behaviors of failure.

Availability is the proportion of time a machine or a system is available out of the time it should be possible. It increased by minimizing unplanned downtime and changeover times. In contrast, the reliability of a system is the probability that it will perform or operate the required functions without failure under a given condition for an intended operating period(Ghodrati, 2005). Lower reliability means increased unplanned stoppages and, consequently, unscheduled repairs and decreased availability(Tatis, 2012). Forgiven equipment, safety is measured by calculating its mean time between failure (MTBF) or mean time to failure (MTTF), and mean time to repair (MTTR)(Deka \& Nath 2015). MTTF used for non-repairable components, for instance, electrical equipment like drive motor, while MTBF used for repairable elements, for example, a rotating shaft or a pulley belt(Kiyak, 2011). MTTR is the time it takes to run a repair after the occurrence of a failure. MTBF and MTTR are two critical key performance indicators (KPIs) when it comes to the availability of a system, facility, equipment, or process. The formulas for determining MTBF and MTTR given in equations (1) and (2), respectively:

$$
M T B F=\frac{\text { Operating Time }}{\text { Number of Failures }}
$$

$M T T R=\frac{\text { Downtime }}{\text { Number of Failures }}$ 
Reliability, $\mathrm{R}(\mathrm{t})$, is the reliability of a system or a piece of equipment at time $\mathrm{t}$ (Modarras,2019). To understand safety, let's consider a production plant operating on 12 hours shift per day. In this situation, $\mathrm{t}$ is 12 hours, and $\mathrm{R}(\mathrm{t})$ is the probability that the production plant will perform its desired functions without any downtime due to machine failure. The general formula for the reliability function of the exponential distribution is given in equation (3) Mitra(2016):

$$
R(t)=e^{\left(-\frac{t}{M T B F}\right)}=e^{(-\lambda t)}
$$

Where $\lambda=\frac{1}{M T B F}=$ failure rate

The lambda, $\lambda$, in the reliability equation (3) represents the failure rate (failures/hour). There is an assumption of random independent failures, which is generally useful for electronic components in computers but might not apply to everything, especially mechanical components. An issue with $\lambda$ is that a constant failure rate is a bit of fiction. If we look at a graph of failure rate vs. component age (Figure 2), often called a bathtub curve, we see that the constant failure rate is only valid during the middle of component life. At the beginning (point A to B), according to Mitra(2016), components have a high failure rate due to manufacturing defects that manage to pass the test but make them part of wearing out very quickly. It is often called the "burning phase" and can last 1 hour, or 10 hours, or 100 hours depending on the system. After burning, the useful product life does indeed provide a more or less constant $\lambda$. Considering only the flat part of the curve (point B to C), equation (3) is used to determine the reliability of the useful product life.

\subsection{Maintainability}

Another critical parameter is machine maintainability. Maintenance usually performed by skilled personnel using prescribed procedures and resources (Reliability Analysis Center). It is typically measured by mean time to repair (MTTR) calculation using equation (2).

Maintainability is a design attribute closely related to maintenance prevention and goes hand in hand with reliability. According to Gulati\&Smith(2009), both safety and maintainability are designed into the assets to minimize maintenance needs and is done by using reliable components, simplify replacements, and ease inspections. Generally expressed as the probability that a system will restore to running conditions within a given time when the maintenance carried out according to recommended

Figure 2. Typical bathtub curve(Mitra, 2016)

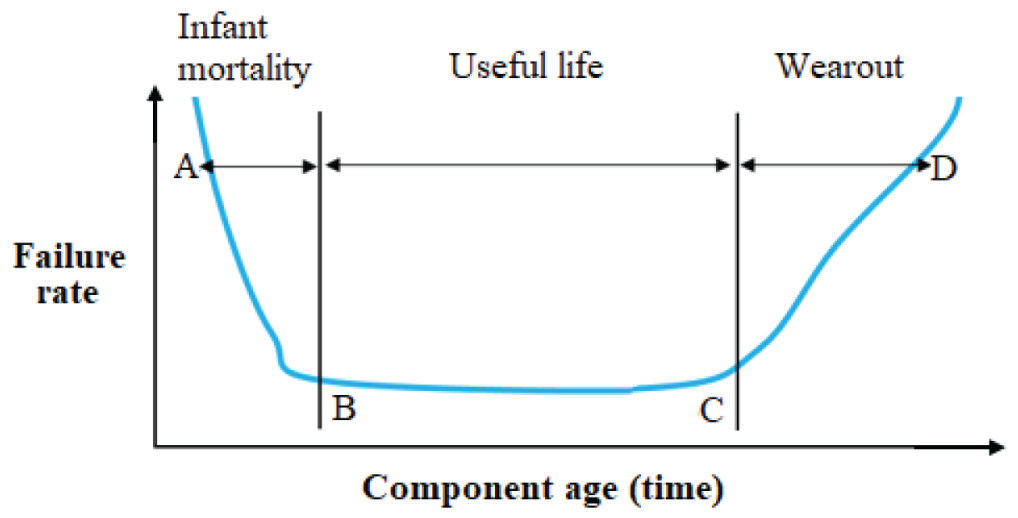


procedures (Haider, 2007). An example of a stated maintainability goal is a $90 \%$ probability that maintenance repair times will complete in 8 hours or less with a maximum repair time of 24 hours, which will require a system MTTR of 3.48 hours (Barringer, 1997).

The maintainability function, $\mathrm{M}(\mathrm{t})$, given in equation (5), can be used to determine the probability of performing a maintenance action for a system with the repair times exponentially distributed [23]. High reliability (few failures) and high maintainability (predictable maintenance times) result in a highly effective production system:

$$
M(t)=1-e^{\left(-\frac{t}{M T T R}\right)}
$$

where:

$\mathrm{t}=$ allowable downtime

MTTR $=$ expected downtime (mean time to repair)

The expected downtime for repair includes waiting time for repairs, time spent doing repairs, and time spent testing and getting the equipment ready to resume operation.

\section{EFFECT OF PREVENTIVE MAINTENANCE ON MACHINE RELIABILITY}

\subsection{Maintenance Strategy}

Heineken South Pacific Brewery at Lae, Papua New Guinea, has two production departments, brewing and packaging, and one support department, engineering. The packaging is the final manufacturing stage where the beer is processed into cans and bottles and comprises two processing plants, the canning, and the bottling plants. The plant fully automated with a capacity to produce up to 150,000 cartons of beer products every week to meet both local and international market demands. Both these plants have the aim of increasing productivity by effectively utilizing their available production time.

To support and maintain a breakdown-free production line, the goal of the maintenance team is to (1) effectively execute all PM activities during scheduled stops (planned downtime), and (2) decrease the time used up to fix a machine or a particular component during breakdown (unplanned downtime). The execution of all preventive maintenance activities is time-driven. The maintenance tasks based on elapsed time or hours of operation; $t$ is scheduled every Monday from 0800 to 1700 hours. Two sets of tasks performed: first are those immediate tasks based on work orders (WO) created through failure tags raised by the production team, for instance, a ticket raised on a conveyor lubrication spray nozzle not spraying during regular operation. The second set of tasks are those that are performed based on recommendations in the manufacturer's service manual, for instance, change lubrication of rolling element bearings after 60 working days. All tasks aimed to maintain machines or components at optimal conditions so that the likelihood of a failure reduced. Figure 3 shows the maintenance strategy applied at the brewery.

\subsection{Downtime Data}

Figure 4 shows the layout of the major equipment on the bottling plant. Although there is an established maintenance program to cater to the maintenance needs of this equipment, the production plant is still plagued by delays due to frequent breakdowns, an increase in time taken to fix a failed machine or component, and a low mean time to repair (MTTR). Information obtained from the brewery's online data recording software, IVAMs, and historical breakdown data from the maintenance team shows that there has been a significantly high number of unplanned, disruptive stoppages that had 


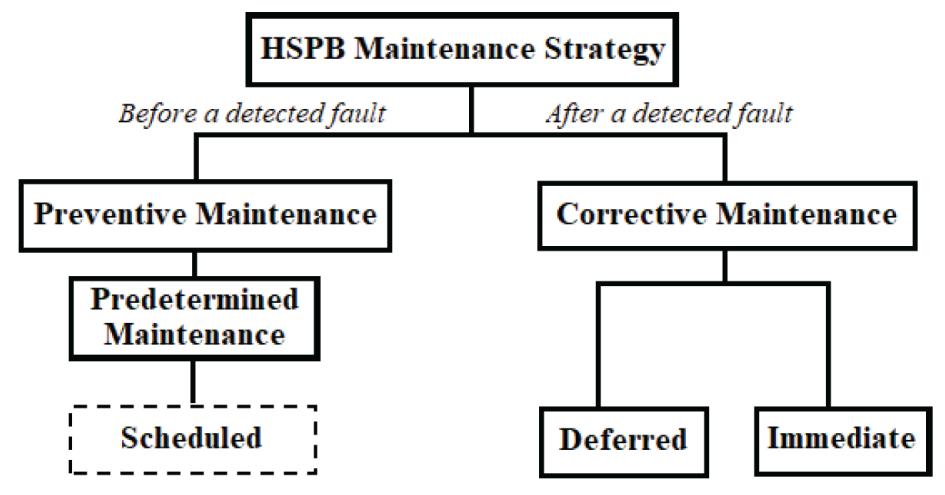

a significant impact on production output. Based on the breakdown hours and several breakdown events registered for each machine, the mean time between failures (MTBF), mean time to repair (MTTR), and failure rate $(\lambda)$ values for the individual device calculated using equations (1), (2), and (4) respectively. These data then used to determine the reliability of each machine for a 12- and 24-hours operation using equation (3). Table 1 provides a summary of these calculations.

A critical machine in any production plant is one with the highest number of breakdown events and has the most extended downtime. Based on Table 1, the bottle packer identified as the plant's critical machine with 127 breakdown events and 104.52 downtime hours. The empty bottle inspector and palletizer machines are considered second and third essential machines with breakdown times of 58.98 and 39.30 hours, respectively.

\subsection{Reliability Analysis}

Reliability, $\mathrm{R}(\mathrm{t})$, of the bottling plant is the probability that the plant will continue to operate for a given time, for instance, 12 hours of a shift, without any downtime due to machine failure. The closer the reliability value is closer to 1 , the higher the chances of the plant's ability to perform appropriately. The reliability determined by calculating the reliability of all the proper equipment that makes up the production plant.

From equation (4), lambda values for each machine that broke down for the six months determined, and the result given in Table 1 . With the $\lambda$ values, the reliability of equipment calculated using equation (3) for different time intervals ( $t=12$ and 24 hours). The reason behind finding the reliability on a 12 hours interval is because the company currently has a 12 hours/shift, 24 hours/day, six days/ week continuous operation with only 9 hours of every Monday scheduled for executing preventive maintenance tasks. Any disruptive stops that occur during production approached as breakdown maintenance (or immediate corrective maintenance).

The implication of the exponential equation, (3), is that it is much harder to successfully sustain and complete a long production uptime than a short one. What this means is that operating a production plant with zero failure for several hours is a lot harder than running without failure for one hour. The illustrated in Figure 5. The graph shows a decrease in the reliability of individual machines on the plant as time goes from 12 to 24 hours, which ultimately results in low plant reliability. From Table 1 , This shows that the longer the MTBF of a machine, the more reliable the equipment. For instance, pasteurizer $(\mathrm{MTBF}=126.046$ hours $)$ is more reliable than the bottle packer (MTBF=20.248 hours).

\subsection{Bottling Plant Reliability in 12 and 24 Hours}

The overview of the bottling plant (Figure 4) shows that the machines in the production plant arranged in series. Note that carton formers 1 and 2, carton check weighs 1 and 2, and carton sealers/coders 
Table 1. Machine downtime data include calculated $\lambda$ and reliability values for $t=12$ and 24 hours

\begin{tabular}{|c|c|c|c|c|c|c|c|}
\hline Machine & $\begin{array}{c}\text { Breakdown } \\
\text { Time (hr) }\end{array}$ & $\begin{array}{c}\text { Breakdown } \\
\text { Events }\end{array}$ & $\begin{array}{c}\text { MTBF } \\
\text { (hr) }\end{array}$ & $\begin{array}{c}\text { MTTR } \\
\text { (hr) }\end{array}$ & $\lambda$ & $\begin{array}{c}\mathbf{R}(\mathbf{t}), \\
\mathbf{t}=12 \\
(\mathbf{h r})\end{array}$ & $\begin{array}{c}R(t), \\
t=24 \\
(h r)\end{array}$ \\
\hline Bottle Packer & 104.520 & 127.000 & 20.248 & 0.823 & 0.049 & 0.553 & 0.306 \\
\hline Empty Bottle Inspector & 58.980 & 25.000 & 104.681 & 2.359 & 0.010 & 0.892 & 0.795 \\
\hline Palletizer & 39.300 & 30.000 & 87.890 & 1.310 & 0.011 & 0.872 & 0.761 \\
\hline Pasteurizer & 29.030 & 21.000 & 126.046 & 1.382 & 0.008 & 0.909 & 0.827 \\
\hline Bottle Labeler & 28.150 & 32.000 & 82.745 & 0.880 & 0.012 & 0.865 & 0.748 \\
\hline Bottle Filler & 28.070 & 35.000 & 75.655 & 0.802 & 0.013 & 0.853 & 0.728 \\
\hline Depalletiser & 26.930 & 30.000 & 88.302 & 0.898 & 0.011 & 0.873 & 0.762 \\
\hline Bottle Washer & 25.550 & 23.000 & 115.237 & 1.111 & 0.009 & 0.901 & 0.812 \\
\hline Empty Bottle Conveyor 2A & 17.450 & 28.000 & 94.948 & 0.623 & 0.011 & 0.881 & 0.777 \\
\hline Label Coder & 14.530 & 8.000 & 332.684 & 1.816 & 0.003 & 0.965 & 0.930 \\
\hline Shrink Packer & 11.830 & 11.000 & 242.197 & 1.075 & 0.004 & 0.952 & 0.906 \\
\hline Depalletiser (pallet discharge) & 8.980 & 10.000 & 266.702 & 0.898 & 0.004 & 0.956 & 0.914 \\
\hline Empty Bottle Conveyor 1A & 8.530 & 12.000 & 222.289 & 0.711 & 0.004 & 0.947 & 0.898 \\
\hline Full Bottle Conveyor 4B & 7.320 & 11.000 & 242.607 & 0.665 & 0.004 & 0.952 & 0.906 \\
\hline Heuft Inspector 2 (FBI 2) & 5.900 & 6.000 & 445.017 & 0.983 & 0.002 & 0.973 & 0.947 \\
\hline Full Bottle Conveyor 3A & 5.900 & 2.000 & 1335.050 & 2.950 & 0.001 & 0.991 & 0.982 \\
\hline Carton Former 1 & 4.620 & 8.000 & 333.923 & 0.578 & 0.003 & 0.965 & 0.931 \\
\hline Carton Coder & 3.930 & 8.000 & 334.009 & 0.491 & 0.003 & 0.965 & 0.931 \\
\hline Full Bottle Conveyor 4A & 3.900 & 5.000 & 534.420 & 0.780 & 0.002 & 0.978 & 0.956 \\
\hline Heuft Inspector 1 (FBI 1) & 2.980 & 5.000 & 534.604 & 0.596 & 0.002 & 0.978 & 0.956 \\
\hline Check Weigher & 2.850 & 2.000 & 1336.575 & 1.425 & 0.001 & 0.991 & 0.982 \\
\hline Carton Sealer & 2.780 & 4.000 & 668.305 & 0.695 & 0.001 & 0.982 & 0.965 \\
\hline Full Bottle Conveyor 3B & 2.150 & 2.000 & 1336.925 & 1.075 & 0.001 & 0.991 & 0.982 \\
\hline Bottle Crowner & 1.730 & 2.000 & 1337.135 & 0.865 & 0.001 & 0.991 & 0.982 \\
\hline Full Bottle Conveyor 2B & 1.650 & 4.000 & 668.588 & 0.413 & 0.001 & 0.982 & 0.965 \\
\hline Full Bottle Conveyor 1B & 0.880 & 2.000 & 1337.560 & 0.440 & 0.001 & 0.991 & 0.982 \\
\hline Empty Bottle Conveyor 2B & 0.670 & 1.000 & 2675.330 & 0.670 & 0.0004 & 0.996 & 0.991 \\
\hline Empty Bottle Conveyor 3A & 0.400 & 2.000 & 1337.800 & 0.200 & 00.001 & 0.991 & 0.982 \\
\hline Empty Bottle Conveyor 2C & 0.370 & 1.000 & 2675.630 & 0.370 & 0.0004 & 0.996 & 0.991 \\
\hline Empty Bottle Conveyor 5 & 0.370 & 1.000 & 2675.630 & 0.370 & 0.0004 & 0.996 & 0.991 \\
\hline Packer & 0.350 & 1.000 & 2675.650 & 0.350 & 0.0004 & 0.996 & 0.991 \\
\hline Coder & 0.350 & 1.000 & 2675.650 & 0.350 & 0.0004 & 0.996 & 0.991 \\
\hline Empty Bottle Conveyor 4 & 0.230 & 1.000 & 2675.770 & 0.230 & 0.0004 & 0.996 & 0.991 \\
\hline TOTAL & 451.180 & 461.000 & 4.826 & 0.979 & & & \\
\hline
\end{tabular}




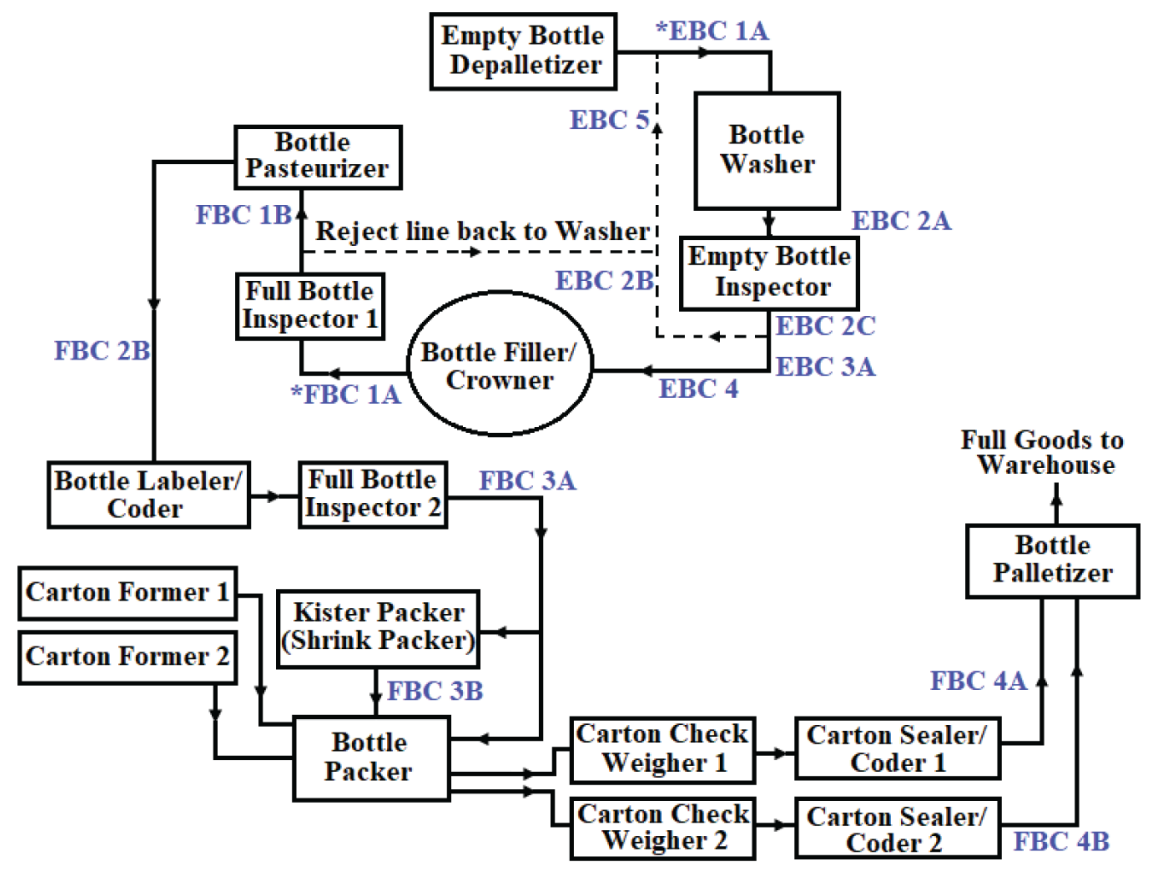

* $E B C$, * FBC - empty bottle conveyor, full bottle conveyor.

Figure 5. Reliability vs. bottling plant machines at 12 and 24 hours

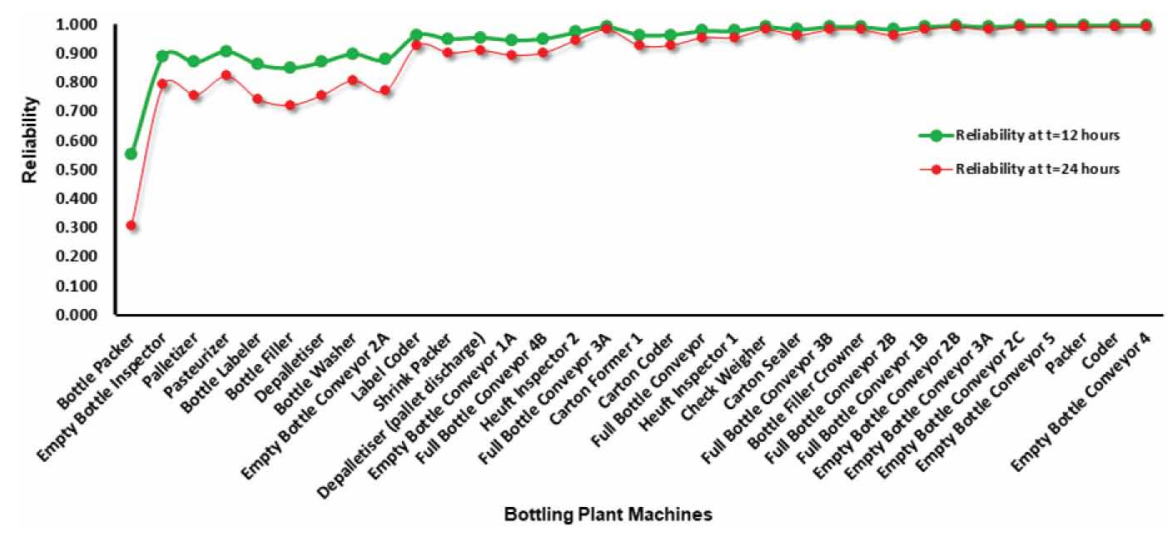

1 and 2 are considered as one unit because the design of the line is such that if one of the pair stops due to a component or system failure, the performance of the plant is severely affected. For instance, if carton former one fails, then package former 2 is the only one available to support bottle packer with erected boxes. This results in the bottle packer operator continuously transferring constructed boxes from lanes 1 to 2 , and in the process, there is a delay in meeting the required quantity per hour. Figure 6 is a simplified block diagram of the line for reliability calculations.

Where the numbers represent (1) bottle packer, (2) empty bottle inspector, (3) palletizer, (4) pasteurizer, (5) bottle labeler, (6) bottle filler, (7) depalletize, (8) bottle washer, (9) empty bottle 


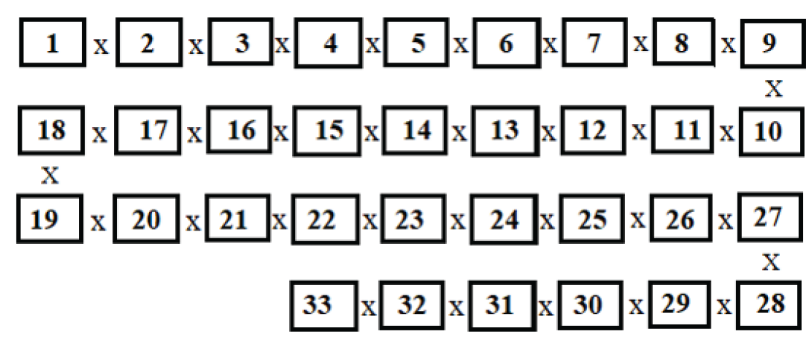

conveyor 2A, (10) label coder, (11) shrink packer, (12) depalletize (pallet discharge), (13) empty bottle conveyor 1A, (14) full bottle conveyor 4B, (15) heuft inspector 2 (FBI 2), (16) full bottle conveyor $3 \mathrm{~A},(17)$ carton former 1, (18) carton coder, (19) full bottle conveyor 4A, (20) heuft inspector 1 (FBI 1), (21) check weigh, (22) carton sealer, (23) full bottle conveyor 3B, (24) bottle filler crowner, (25) full bottle conveyor 2B, (26) full bottle conveyor 1B, (27) empty bottle conveyor 2B, (28) empty bottle conveyor 3A, (29) empty bottle conveyor 2C, (30) empty bottle conveyor 5, (31) packer, (32) coder, (33) empty bottle conveyor 4.

Equation (6) used to calculate the reliability of machines or components in series. It is the multiplication of the reliabilities of the individual devices in the series:

$$
\text { Reliability }_{\text {Series }}=R_{1}^{*} R_{2} * R_{3} * \ldots R_{n}
$$

where $R_{1}, R_{2}, R_{3}, R_{n}$ are the reliabilities of machines $1,2,3$ through to $\left(n^{\text {th }}\right)$ machine. Therefore, using Table 1 the reliability of the plant at $\mathrm{t}=12$ hours is:

$\mathrm{R}(12)=0.553 * 0.892 * 0.872 * 0.909 * 0.865 * 0.853 * 0.873 * 0.901 * 0.881 * 0.965 * 0.952 * 0.956 * 0.947 *$

$0.952 * 0.973 * 0.991 * 0.965 * 0.965 * 0.978 * 0.978 * 0.991 * 0.982 * 0.991 * 0.991 * 0.982 * 0.991 * 0.996 *$

$0.991 * 0.996 * 0.996 * 0.996 * 0.996 * 0.996$

$=0.1223 * 100$

$=12.23 \%$

Reliability at $\mathrm{t}=24$ hours:

$\mathrm{R}(24)=0.306 * 0.795 * 0.761 * 0.827 * 0.748 * 0.728 * 0.762 * 0.812 * 0.777 * 0.930 * 0.906 * 0.914 * 0.898 *$ $0.906 * 0.947 * 0.982 * 0.931 * 0.931 * 0.956 * 0.956 * 0.982 * 0.965 * 0.982 * 0.982 * 0.965 * 0.982 * 0.991 *$

$0.982 * 0.991 * 0.991 * 0.991 * 0.991 * 0.991$

$=0.0149 * 100$

$=1.49 \%$

\subsection{Machine Breakdown Analysis}

As an approach to understanding why equipment or components on the bottling plant failed, a breakdown analysis (BDA) performed on the machine with the highest breakdown events. The bottle packer, with downtime events of 127 , was selected for the study. The purpose of a BDA is to identify the root cause behind a failed component to implement countermeasures that will prevent failures from reoccurring. Machine downtimes lead to low overall equipment effectiveness (OEE); therefore, 
it is essential that once a component fails, the failure modes identified and correct preventive actions are put in place to eliminate the problem. Table 2 lists the ingredients of the bottle packer that failed during the six months, the basic description of the function of each component, and the failure mode that resulted in a machine breakdown.

From catastrophe mode repeatedly affecting bottle packing machine, results indicated ineffective preventive maintenance. Because the plant set to operate on 12 hours per shift, 24 hours per day, continuous operation for almost every single week, the maintenance team hardly has enough time to complete all PM tasks. Additionally, a lack of understanding of the root cause of equipment failure from the planned maintenance team results in ineffective planning and execution of maintenance tasks during the 9 hours of scheduled downtime every Monday. Hence, almost all failure modes are associated with either damaged or worn parts. For instance, the issue with cylindrical grippers not picking up bottles during production is an on-going problem related to damage grippers caused by fluctuation in working air (compressed air). The maintenance team goes into fire-fighting mode every time the gripper issue arises, which always results in heavy downtime to the plant.

Lack of spare parts for the major components of the bottle packer is another factor that contributed to increased downtime. Its fact, in the case of the rectangular grippers on the packing head for $4 \times 6$ shrink packs. The issue with a fallen six-pack is so common that it has now accepted as a norm. A closer look at the component shows severe damage to the rubber-protected edges of the grippers. Many order tags have raised by production operators indicating worn parts needing immediate replacement, but the response they get from the maintenance team is the unavailability of spare parts. A robust preventive maintenance program is one that has an effective tracking system for spare part availability to support a continuous operation. Since the operation of the bottle packing machine is continuous and functions on a 24/7 basis, the role of the maintenance planning team is critical to improving machine operation in achieving improved plant reliability.

\subsection{Relationship Between Failure Rate and Maintenance}

The failure rate of the machines on the bottling plant increased with time during the six months of operation. The effect of performing less preventive maintenance tasks on the machines because the plant is operated continuously for 24 hours, six days a week, the machines work for longer times, whereby the failure rate of their components increases to the point that results in equipment failure. As machine or component failure rate increases, more corrective actions are required hence reducing the reliability of the production plant.

Figure 7 shows the cumulative failure rate of machines on the plant. There are two curves shown, red and green. The red curve indicates a cumulative failure rate of machines before autonomous maintenance (AM), and countermeasures introduced as part of developing an effective PM program for the components of critical machines that were prone to reoccurring breakdowns due to wear and tear. Based on BDA analysis performed on the bottle packer, root causes of failed components identified. Maintenance tasks then planned and executed accordingly. Detailed checklists designed for periodic inspection lead to the effective planning of parts maintenance and replacement on the bottle packing machine as well as the other two critical machines. The countermeasures (regular inspection, replacement of worn parts, detailed PM, lubrication, and tightening) planned and performed over two months. Improvement made, with a decline in plant cumulative failure rate (green curve), as shown in Figure 7.

\section{RESULTS AND DISCUSSION}

Recommendations were put forward for countermeasures to developed for the bottle packer as part of establishing an effective PM program for plant reliability improvement. All achieved by setting up an autonomous maintenance (AM) team to carry out continuous improvement activities periodically daily on the main components of the bottle packer. The team comprised three highly experienced 
Table 2. Components of bottle packer and their failure modes that resulted in machine breakdown

\begin{tabular}{|c|c|c|c|}
\hline Machine component & Component function & Functional failure & Failure mode \\
\hline $\begin{array}{l}\text { Human machine interface } \\
\text { (HMI) }\end{array}$ & $\begin{array}{l}\text { A touch screen that displays information about } \\
\text { machine state. The application software accepts and } \\
\text { implements operator's control instructions. }\end{array}$ & HMI screen freezed. & $\begin{array}{l}\text { Loose ethernet } \\
\text { connection cable on } \\
\text { Communication module. }\end{array}$ \\
\hline $\begin{array}{l}\text { Gripper head (for individual } \\
\text { bottles) }\end{array}$ & $\begin{array}{l}\text { Moves over the bottle table and the cylindrical } \\
\text { grippers pick up the bottles. Then moves with the } \\
\text { bottles over the carton conveyor and places the bottles } \\
\text { in the cartons. The grippers return, cartons discharge, } \\
\text { and the cycle continues. }\end{array}$ & $\begin{array}{l}\text { Between } 4 \text { to } 12 \text { cylindrical } \\
\text { grippers not picking up } \\
\text { bottles (total } 192 \text { grippers) }\end{array}$ & $\begin{array}{l}\text { Damaged or worn } \\
\text { suction heads. }\end{array}$ \\
\hline $\begin{array}{l}\text { Packing head (for } 4 \times 6 \text { shrink } \\
\text { packs) }\end{array}$ & $\begin{array}{l}\text { Moves over the shrink six pack table, and the } \\
\text { rectangular grippers pick up the packs. Then moves } \\
\text { with the packs over the carton conveyor and places } \\
\text { the packs in the cartons. The grippers return after } \\
\text { releasing the packs, cartons discharge, and the cycle } \\
\text { continues. }\end{array}$ & $\begin{array}{l}2 \text { to } 4 \text { rectangular grippers } \\
\text { continuously dropping six } \\
\text { packduring transfer (total } \\
32 \text { rectangular grippers) }\end{array}$ & $\begin{array}{l}\text { Damaged or worn } \\
\text { rectangulargrippers. }\end{array}$ \\
\hline Switching flags & $\begin{array}{l}\text { Actuators that enable all lanes on the bottle table to be } \\
\text { completely filled with bottles, ensuring that the full } \\
\text { number of bottles for the packing process is reached } \\
\text { before the grippers pick up the bottles. }\end{array}$ & $\begin{array}{l}\text { Switching flags not } \\
\text { actuated, continuously } \\
\text { stopping the machine. }\end{array}$ & $\begin{array}{l}\text { Damaged or broken } \\
\text { flag. }\end{array}$ \\
\hline Correction frame & $\begin{array}{l}\text { A metal frame with plastic aprons that centers the } \\
\text { empty cartons in the packing zone before the gripper } \\
\text { (or packing) head deposits the bottles (or six packs) } \\
\text { into the cartons. }\end{array}$ & $\begin{array}{l}\text { Empty cartons not } \\
\text { positioned or centered } \\
\text { correctly. }\end{array}$ & $\begin{array}{l}\text { Damaged centering } \\
\text { aprons. }\end{array}$ \\
\hline Safety door & $\begin{array}{l}\text { Secures the production area of the machine against } \\
\text { unauthorized entry. A message is sent to the central } \\
\text { processing unit (CPU) if a safety door to the secured } \\
\text { area is opened, and the CPU triggers an emergency } \\
\text { stop for the components in the secured area. }\end{array}$ & $\begin{array}{l}\text { Unable to lock/unlock } \\
\text { main sliding door. CPU } \\
\text { not permitting machine for } \\
\text { production. }\end{array}$ & $\begin{array}{l}\text { Loose and damaged } \\
\text { cable for operating } \\
\text { controls on actuation } \\
\text { housing. }\end{array}$ \\
\hline Infeed mat conveyor & $\begin{array}{l}\text { Six pack conveyor that moves packs into the packing } \\
\text { zone (receiving position) of the packing head. }\end{array}$ & $\begin{array}{l}\text { Mat conveyor not running, } \\
\text { unable to deliver six packs } \\
\text { to the receiving table. }\end{array}$ & $\begin{array}{l}\text { Broken mat links due to } \\
\text { wear and fatigue stress. }\end{array}$ \\
\hline Carton conveyor & $\begin{array}{l}\text { Transports the cartons into and out of the packing } \\
\text { zone. The conveyor is made of plastic chains and are } \\
\text { rotated by chain wheels seated on a primary and tail } \\
\text { shafts. A motor drives the primary shaft via a gearing } \\
\text { mechanism. }\end{array}$ & Conveyor stopped running. & $\begin{array}{l}\text { Worn, damaged chain } \\
\text { links. }\end{array}$ \\
\hline $\begin{array}{l}\text { Infeed geared motor for carton } \\
\text { conveyor }\end{array}$ & $\begin{array}{l}\text { Supplies motive power to a primary shaft that drives } \\
\text { the conveyor chains to transport cartons into and out } \\
\text { of the packing zones. }\end{array}$ & $\begin{array}{l}\text { Motor failed to supply } \\
\text { motive power to primary } \\
\text { shaft. Motor makes high } \\
\text { vibrating noise. }\end{array}$ & Ceased bearing. \\
\hline $\begin{array}{l}\text { Pneumatic cylinders on } \\
\text { packing head }\end{array}$ & $\begin{array}{l}\text { Pneumatically controlled device on the packing head } \\
\text { that control the movement of grippers (cylindrical } \\
\text { cups or rectangular grippers). They control the } \\
\text { grippers to open and close pneumatically to pick up } \\
\text { and deposit bottles or six packs. }\end{array}$ & $\begin{array}{l}\text { Shaft on the pneumatic } \\
\text { cylinders unable to open } \\
\text { and close thereby unable to } \\
\text { control gripper movement. }\end{array}$ & $\begin{array}{l}\text { Faulty reed switch on } \\
\text { pneumatic cylinders. }\end{array}$ \\
\hline Air supply unit & $\begin{array}{l}\text { Compressed air supply connected to the maintenance } \\
\text { unit of the bottle packer. The maintenance unit } \\
\text { supplies the pneumatic machine components with } \\
\text { working air. }\end{array}$ & $\begin{array}{l}\text { Packing head dropping } \\
\text { bottles (or six packs) due to } \\
\text { insufficient air supply. }\end{array}$ & $\begin{array}{l}\text { Dirty air filter on the } \\
\text { maintenance unit. }\end{array}$ \\
\hline Synchronous belts & $\begin{array}{l}\text { Toothed belt pulleys that connect lifting frame, } \\
\text { counterweights, and lifting unit. The lifting frame } \\
\text { is raised or lowered according to the lifting unit's } \\
\text { direction of rotation. The belt tension is monitored by } \\
\text { synchronous belt controls. }\end{array}$ & $\begin{array}{l}\text { Lifting unit not working. } \\
\text { Unable to raise or lower } \\
\text { Lifting frame. }\end{array}$ & $\begin{array}{l}\text { Worn application rollers } \\
\text { causing belt to slip off } \\
\text { position. }\end{array}$ \\
\hline Field bus cable & $\begin{array}{l}\text { System network for real-time distributed control for } \\
\text { the bottle packer. Field bus connection for bottle and } \\
\text { carton transport. }\end{array}$ & $\begin{array}{l}\text { Unable to transport cartons } \\
\text { into and out of the packing } \\
\text { zone. HMI indicated } \\
\text { faulty bus slave cable and } \\
\text { conveyor stops running. }\end{array}$ & $\begin{array}{l}\text { Faulty field bus } \\
\text { connecting cable. }\end{array}$ \\
\hline
\end{tabular}


Figure 7. Cumulative failure rate of equipment on the bottling plant

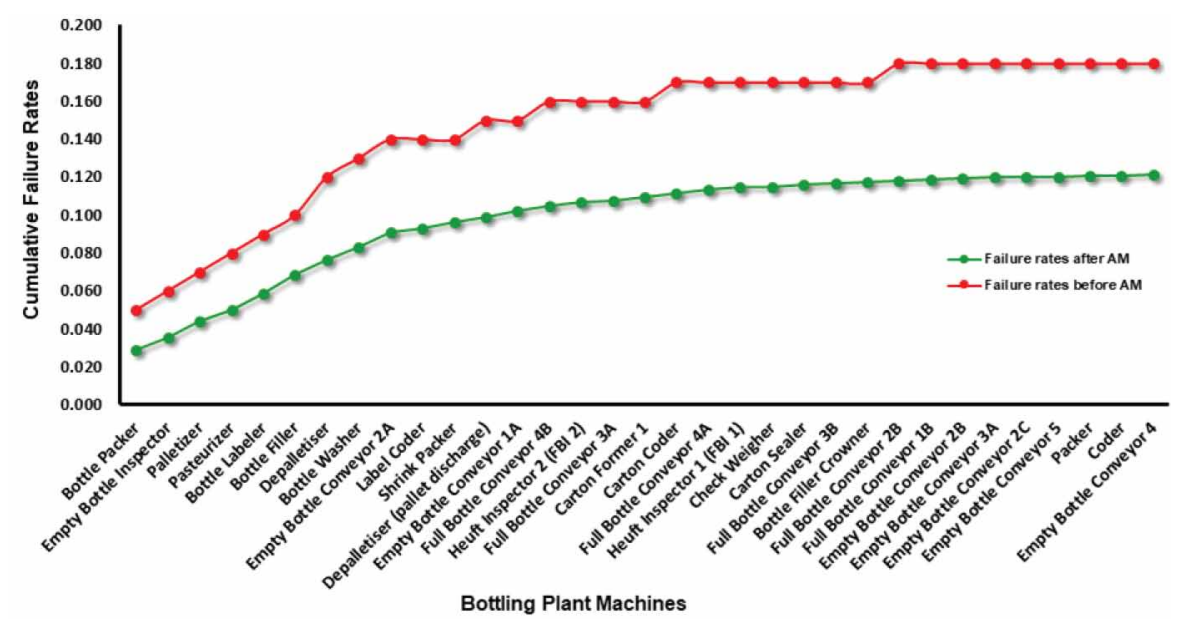

operators from the production team, one electrical specialist and one mechanical shift technician from the engineering team, and one production supervisor as a team leader to provide overall supervision. Checklists planed for the machine's critical components that prone to reoccurring breakdowns due to wear and tear. Additional preventive maintenance activities were also planned for two other essential machines, EBI, and palletizer, having the second and third highest breakdown hours. Apart from the 9 hours of PM stop every Mondays, for periodic inspection and maintenance carried out during planned stops (changeover, daily cleaning, inspection, lubrication, and tightening) for two months and the results showed improvement with a noticeable decrease in breakdown events and downtime and an increase in MTBF on these machines. Figure 8 shows these results.

From Table 1 and Figure 8, the total breakdown time for the bottle packer reduced from 104.52 hours to 93.41 hours. The same trends also observed on the empty bottle inspector and palletizer. EBI breakdown was reduced from 58.98 hours to 47.29 hours, while palletizer from 39.30 hours to 31.06 hours. Table 3 shows the results. A noticeable increase in MTBFs on the critical machines observed. MTBF of bottle packer increased from 20.248 hours to 34.730 hours, EBI and palletizer machines had their MTBFs increased from 104.681 and 87.890 hours to 143.550 and 120.160 hours, respectively. The higher the MTBF, the more reliable the machine.

Figure 8. Breakdown time vs machines on the bottling plant

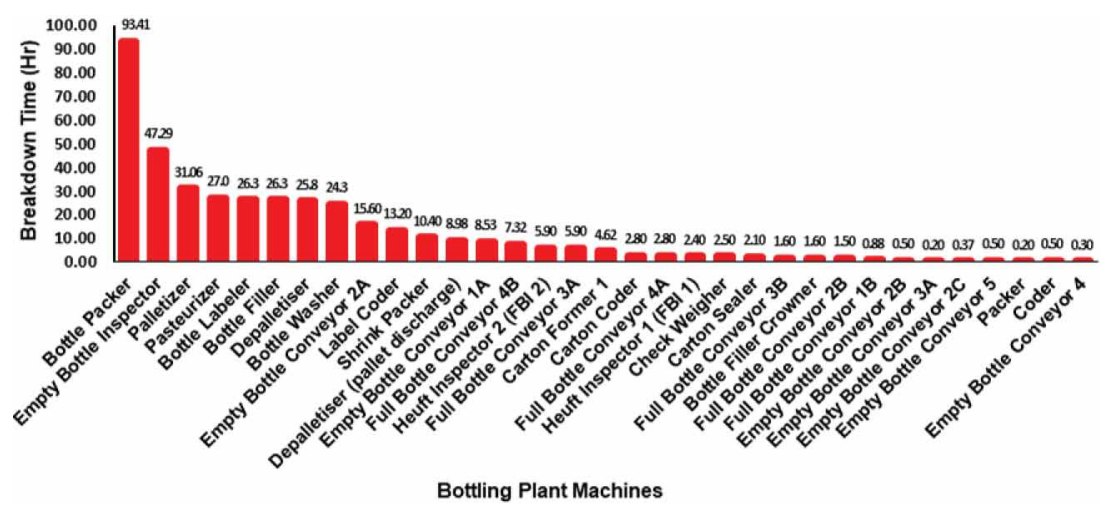


Table 3. Critical machine downtime data

\begin{tabular}{|l|l|l|l|l|l|l|l|}
\hline \multicolumn{1}{|c|}{ Machine } & \multicolumn{1}{|c|}{$\begin{array}{c}\text { Time } \\
\text { (hr) }\end{array}$} & \multicolumn{1}{|c|}{$\begin{array}{c}\text { Breakdown } \\
\text { Events }\end{array}$} & $\begin{array}{c}\text { MTBF } \\
(\mathbf{h r})\end{array}$ & $\begin{array}{c}\text { MTTR } \\
(\mathbf{h r})\end{array}$ & $\begin{array}{c}\mathbf{R}(\mathbf{t}), \\
\mathbf{t}=\mathbf{1 2} \\
(\mathbf{h r})\end{array}$ & $\begin{array}{c}\mathbf{R}(\mathbf{t}) \mathbf{2} \\
\mathbf{t}=\mathbf{2 4} \\
(\mathbf{h r})\end{array}$ \\
\hline Bottle Packer & 93.41 & 102.00 & 34.730 & 0.920 & 0.029 & 0.708 & 0.501 \\
\hline Empty Bottle Inspector & 47.29 & 25.000 & 143.550 & 1.890 & 0.007 & 0.920 & 0.846 \\
\hline Palletizer & 31.06 & 30.000 & 120.160 & 1.040 & 0.008 & 0.905 & 0.819 \\
\hline
\end{tabular}

Under AM program, operators of critical machines selected based on the expert on those machines bottle packer, EBI, and palletizer, were empowered to perform adjustments and minor maintenances (cleaning, inspection, lubrication, tightening) on a day to day basis. Analysis of machine reliability delivered after two months of rolling out the AM program, and the result showed improvement in reliabilities of the critical machines. The reliability of bottle packer increased from $55.30 \%$ to $70.80 \%$, while EBI and palletizer from $89.20 \%$ and $87.20 \%$ to $92 \%$ and $90.50 \%$, respectively. Figure 9 results show some improvements observed in other machines on the plant. Red and green bars represent machine reliabilities before and after the AM program, respectively.

\section{CONCLUSION}

The regular adoption and use of modern technology, the change inlatency of business processes makes it more challenging to decide suitable maintenance strategies (Galli, 2018b).In this light this paper investigated the effect of preventive maintenance on the reliabilities of machines on the bottling plant of a beer manufacturing company. The research compiled quantitatively using six months of real-time data. Within this period, the plant was in operation for 111.5 days, an equivalent of 2676 hours of production. The analysis showed a total of 461 breakdown events that caused the company 451.18 hours to lose time in unplanned stoppages. Based on the breakdown events obtained for each machine, mean time between failure (MTBF), mean time to repair (MTTR), and failure rate ( $\lambda$ ) values for individual equipment calculated. The bottle packer identified as the critical machine with the highest of 104.52 hours of breakdown time. A breakdown analysis (BDA) then performed. From the failure mode of all the reoccurring problems affecting this machine, the result indicated mainly ineffective preventive maintenance. The results showed that there is a lack of understanding of the

Figure 9. Machine reliabilities before and after autonomous maintenance

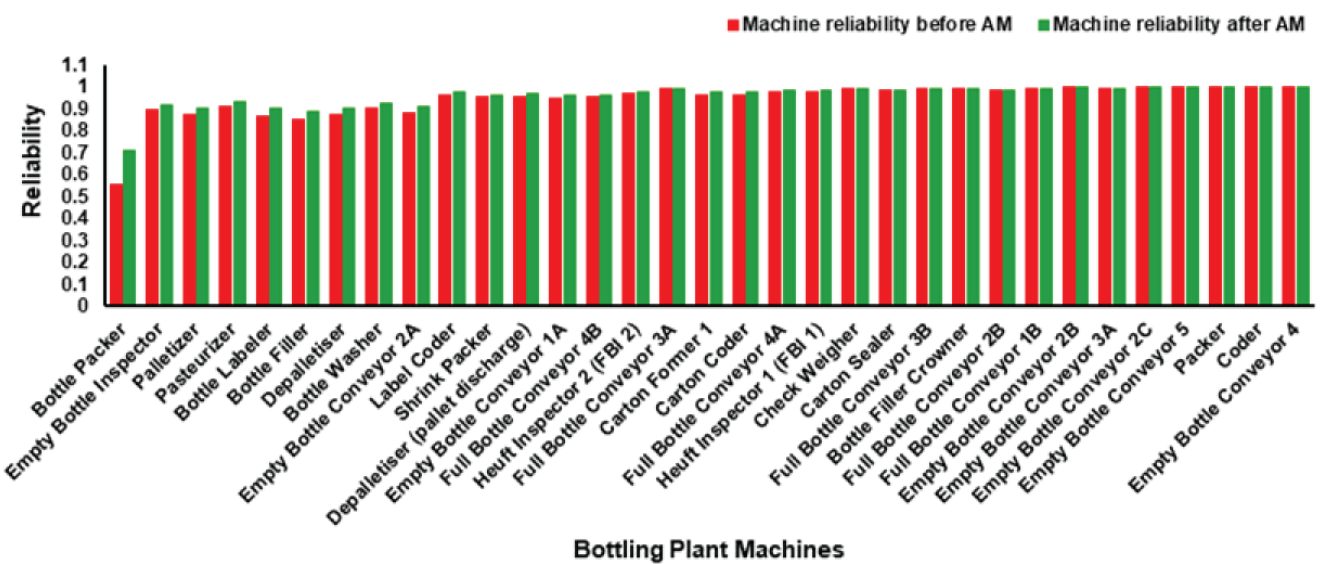


root cause of equipment failure from the planned maintenance team; hence the level of planning, scheduling, and execution of maintenance activities was not fulfilling the requirements for reducing machine breakdowns and time losses on the plant. Furthermore, the analysis showed that the machines on the plant stretched to operate for longer times with less or no scheduled PM activities; hence failure rates of components increased to the point that resulted in unplanned breakdowns.

An autonomous maintenance (AM) team set up as part of establishing an effective PM program to improve the reliabilities of the critical machines that were continually falling. Experienced operators with unique knowledge and skills on several machines were selected to perform adjustments and minor maintenances (cleaning, inspection, lubrication, tightening) on a day to day basis using specifically designed checklists as countermeasures to preventing machine failure. Noticeable reduction in machine breakdowns observed after two months of rolling out the AM program. The total breakdown time for the bottle packer reduced from 104.52 hours to 93.41 hours. The same trends also observed on the empty bottle inspector and palletizer machines. EBI breakdown was reduced from 58.98 hours to 47.29 hours, while palletizer from 39.30 hours to 31.06 hours. As a result, the reliability of bottle packer increased from $55.30 \%$ to $70.80 \%$, while EBI and palletizer from $89.20 \%$ and $87.20 \%$ to $92 \%$ and $90.50 \%$, respectively. 


\section{REFERENCES}

Adale, M. A. (2009). Evaluation of Maintenance Management Through Benchmarking in Geothermal PowerPlants (Master of Science Thesis). Department of Mechanical and Industrial Engineering, University of Iceland.

Barringer, H. P. (1997). Availability, Reliability, Maintainability, and Capability. Barringer\& Associates Inc.

Deka, D., \& Nath, T. (2015). Breakdown and Reliability Analysis in a Process Industry. InternationalJournal of Engineering Trends and Technology, 28(3), 150-156. doi:10.14445/22315381/IJETT-V28P229

Galli, B. J. (2018a). Systems Thinking and Systems Analysis in Six Sigma: A Relational Review. International Journal of System Dynamics Applications, 7(4), 98-112. doi:10.4018/IJSDA.2018100106

Galli, B. J. (2018b). Application of system engineering to project management: How to view their relationship. International Journal of System Dynamics Applications, 7(4), 76-97. doi:10.4018/IJSDA.2018100105

Galli, B. J. (2020). Measurement System Analysis and System Thinking in Six Sigma: How They Relate and How to Use Them. International Journal of System Dynamics Applications, 9(1), 44-62. doi:10.4018/ IJSDA.2020010103

Gulati, R., \& Smith, R. (2009). Maintenance and Reliability Best Practices. Industrial Press.

Ghodrati, B. (2005). Reliability and Operating Environment Based Spare Parts Planning (Doctoral Thesis). Division of Operational and Maintenance Engineering, Luleå University of Technology.

Haddad, M., \& Otayek, R. (2019). Assessing the Sustainment of a Lean Implementation Using System Dynamics Modeling: A Case Study of Apparel Manufacturing in Lebanon. International Journal of System Dynamics Applications, 8(4), 14-29. doi:10.4018/IJSDA.2019100102

Haider, S. J. A. (2007). Role of Maintenance in Component and System Reliability: A Diesel Power GenerationCase Study (Master of Engineering Thesis). Department of Mechanical Engineering, University of Alberta.

Hupjé, E. (2018). How to Choose the Right Maintenance Strategy. https://www.roadtoreliability.com/types-ofmaintenance/\#Corrective_Maintenance_CM

Jessica, R. (2014). Modeling Preventive Maintenance in Complex Systems. Open Access Theses. 244. Retrieved Dec, 2019 from: https://docs.lib.purdue.edu/open_access_theses/244

Kiyak, E. (2011a). The Importance of Preventive Maintenance in terms of Reliability in Aviation Sector. Academic Press.

Kiyak, E. (2011b). Recent Advances in Manufacturing Engineering. Retrieved Dec, 2019 from: https://www. researchgate.net/publication/266492733

Lagnebäck, L. (2007). Evaluation of wayside condition monitoring technologies for condition-based maintenance of railway vehicles (Licentiate Thesis). Department of Civil, Mining and Environmental Engineering, Luleå University of Technology.

Mahmood, S. T. (2011). Use of Vibrations Analysis Technique in Condition Based Maintenance (Master of Science Thesis). Department of Production Engineering, Royal Institute of Technology, Sweden.

Márquez, A. C. (2007). The Maintenance Management Framework: Models and Methods for Complex Systems Maintenance. Springer-Verlag.

Mitra, A. (2016). Fundamentals of quality control and improvement. John Wiley \& Sons.

Mkemai, R. (2011). Maintenance Procedures and Practices for Underground Mobile Mining Equipment (Master of Science Thesis). Department of Civil, Environmental and Natural Resources Engineering, Luleå University of Technology.

Mobley, R. K. (2002). An Introduction to Predictive Maintenance. Butterworth-Heinemann Publications.

Morales, D. K. (2002). CBM Policy Memorandum. Washington, DC: Deputy under Secretary of Defense for Logistics and Material Readiness. 
Nieminen, H. (2016). Improving Maintenance in high-volume manufacturing. Case: Ball Beverage Packaging Europe (Master's Thesis). Lahti University of Applied Sciences.

Nikabadi, M. S., \& Hakaki, A. (2018). A dynamic model of effective factors on open innovation in manufacturing small and medium sized companies. International Journal of System Dynamics Applications, 7(1), 1-26. doi:10.4018/IJSDA.2018010101

Noriega, M. (2019). Review and Classification of Industrial Boilers Maintenance and a Reliability-Centered Maintenance Methodology Proposal for Production Plants (Master of Science Thesis). Department of Electronics, Information and Bioengineering, Polytechnic University of Milan.

Omamo, A. O., Rodriguez, A. J., \& Muliaro, J. W. (2018). A Systems Dynamics Model for Mobile Industry Governance in the Context of the Kenyan Vision 2030. International Journal of System Dynamics Applications, 7(2), 81-100. doi:10.4018/IJSDA.2018040105

Omamo, A. O., Rodrigues, A. J., \& Muliaro, W. J. (2020). A System Dynamics Model of Technology and Society: In the Context of a Developing Nation. International Journal of System Dynamics Applications, 9(2), 42-63. doi:10.4018/IJSDA.2020040103

Olose, E. O. (2016). Effective Maintenance and Reliability Program in the Production of Crude Oil and Natural Gas. International Journal of Scientific and Engineering Research, 7(2), 1048-1056.

Rao, B. K. N. (1996). Handbook of Condition Monitoring. Elsevier Advanced Technology Publications.

Reliability Analysis Center (RAC). (n.d.). Introduction to Operational Availability (A $A_{0}$ ). Author.

Swedish Standard Institute. (2001). SS-EN 13306 - Maintenance terminology. Swedish Standard Institute.

Tatis, R. (2012). Vibration Measurement for Rotatory Machines - Importance of maintenance practices (Bachelor's thesis). HAMK University of Applied Sciences, Finland.

Jacob Ben is currently working fulltime as a Packaging Supervisor with Heineken South Pacific Brewery Limited, Lae Morobe Province, Papua New Guinea. He has a Bachelor degree in Mineral Processing and is working towards completing his masters in mechanical engineering at Papua New Guinea University of Technology. His thesis is about investigating the effect of preventing maintenance on machine reliabilities.

Aezeden Mohamed has B.Sc., M.Sc., and Ph.D. degrees in Mechanical and Manufacturing at the University of Manitoba, Canada. His areas of research are experimental in nature includes but not limited; mechanical properties, materials characterizations, corrosion and corrosion control, and biomedical engineering. He has carried out research and taught at the University of Manitoba and Memorial University in Canada. In addition to his technical research interests, he earned a diploma in Higher Education Teaching from the University of Manitoba, Canada. He has published over 10 papers in the Canadian Engineering Education Association. Currently, he is a Senior Lecturer at the University of Technology, Papua New Guinea.

Kamalakanta Muduli is presently working as Associate Professor in Department of Mechanical Engineering, Papua New Guinea University of Technology, Lae, Morobe Province, Papua New Guinea. He has obtained PhD from School of Mechanical Sciences, IIT Bhubaneswar, Orissa, India, in the area of Green Supply Chain Management. He has obtained Master's degree in Industrial Engineering. He has over 14 years of academic and research experience. He has published 27 papers in peer reviewed international journals and more than 21 papers in National and International Conferences. 